\title{
Sustainable way for enhancing phosphorus efficiency in agricultural soils through phosphate solubilizing microbes
}

\author{
AJEET KUMAR, C.S. CHOUDHARY, DIWAKAR PASWAN, BRIJESH KUMAR AND ANJANA ARUN
}

\author{
MEMBERS OF RESEARCH FORUM: \\ Corresponding author : \\ AJEET KUMAR, Regional Research \\ Station, Agwanpur, SAHARSA (BIHAR) \\ INDIA \\ Email: ajeetbau@gmail.com
}

Co-authors :

C.S. CHOUDHARY, DIWAKAR PASWAN AND ANJANAARUN, Regional Research Station, Agwanpur, SAHARSA (BIHAR) INDIA

BRIJESH KUMAR, Department of Soil Science and Agricultural Chemistry, Mandan Bharti Agriculture College, Agwanpur, SAHARSA (BIHAR) INDIA
Received : 18.09.2014; Accepted : 28.11.2014

Summary

Phosphorus is the second important key element after nitrogen as a nutrient in terms of quantitative plant requirement. Although phosphorus is abundant in soils (organic and inorganic forms), its availability is restricted as it occurs mostly in insoluble forms. The phosphorus content in soil is about 0.05 per cent $(\mathrm{w} / \mathrm{w})$ but only 0.1 per cent of the total phosphorus is available to plant because of poor solubility and its fixation in every type of soil. An adequate supply of phosphorus during early phase of plant development is important for laying down the primordia of plant parts. It plays significant role in root ramification, thereby imparting vitality to plant. It also helps in seed formation and in early maturation of crops. Poor availability or deficiency of phosphorus markedly reduces plant size and growth. Phosphorus accounts about $0.2-0.8$ per cent of the plant dry weight. To satisfy crop requirements, phosphorus is usually added to soil as chemical fertilizer, however, synthesis of chemical fertilizer is highly energy intensive processes, and has long term impacts on the environment in terms of eutrophication, soil fertility depletion, carbon footprint. Moreover, plants use only a small amount of phosphorus, because about 80-90 per cent of added phosphorus is precipitated by metal-cation complexes, and rapidly fixed in soils. Such environmental concerns have led to the search for sustainable way of phosphorus nutrition of crops. In this regards phosphate-solubilizing microorganisms have been seen as best eco-friendly means for phosphorus nutrition of crop. Although, several bacterial (Pseudomonas and Bacilli) and fungal strains (Aspergillus and Penicillium) have been identified as PSM. Their performance under in situ conditions is not reliable and therefore, needs to be improved by using co-inoculation techniques. This review focuses on the diversity of PSM, mechanism of P solubilization, role of various phosphatase, impact of various factors on solubilization, the present and future scenario of their use and potential for application of this knowledge in managing a sustainable agricultural system.

Key words : Soil phosphorus, PSM, Solubilization, Biodiversity, Biofertilizers, Siderophores, TCP, Organic acids

How to cite this article : Kumar, Ajeet, Choudhary, C.S., Paswan, Diwakar, Kumar, Brijesh and Arun, Anjana (2014). Sustainable way for enhancing phosphorus efficiency in agricultural soils through phosphate solubilizing microbes. Asian J. Soil Sci., 9(2): 300-310. 